\title{
Heterozygosity for $A B C A 3$ Mutations Modifies the Severity of Lung Disease Associated with a Surfactant Protein C Gene (SFTPC) Mutation
}

\author{
JANINE E. BULLARD, AND LAWRENCE M. NOGEE
}

Department of Pediatrics, Johns Hopkins University School of Medicine, Baltimore, Maryland 21287

\begin{abstract}
Heterozygous SFTPC mutations have been associated with adult and pediatric interstitial lung disease (pILD). Inheritance is autosomal dominant, but de novo mutations may cause sporadic disease. SFTPC mutations have been associated with variable onset of symptoms, ranging from early infancy to late adulthood. The underlying mechanisms for this variability are unknown. Recently, mutations in $A B C A 3$ (encoding member $\mathrm{A} 3$ of the adenosine triphosphate-binding cassette family of transporters) were identified as a cause of pILD. To test the hypothesis that $A B C A 3$ mutations modify the severity of lung disease in individuals with $S F T P C$ mutations, we sequenced $A B C A 3$ from four symptomatic infants with the same SFTPC mutation, a substitution of isoleucine by threonine in codon 73 (I73T). Each infant developed respiratory symptoms by 2 mo of age and inherited the mutation from an asymptomatic parent. Three of the four infants were also heterozygous for an $A B C A 3$ mutation, which was inherited from the parent without SFTPC I73T. The finding of heterozygosity for $A B C A 3$ mutations in severely affected infants with SFTPC I73T, and independent inheritance from diseasefree parents supports that $A B C A 3$ acts as a modifier gene for the phenotype associated with an SFTPC mutation. (Pediatr Res 62: 176-179, 2007)
\end{abstract}

$\mathrm{P}$ lmonary surfactant is a mixture of lipids and specific proteins that reduces surface tension at the air-liquid interface and prevents end-expiratory atelectasis. Lack of surfactant is the primary cause of respiratory distress syndrome (RDS) in infants born prematurely. Although surfactant phospholipids are primarily responsible for lowering surface tension, two small hydrophobic proteins, surfactant proteins B and C (SP-B and SP-C), have key roles in regulating surfactant function and metabolism (1). SP-C deficiency and mutations in the SP-C gene (SFTPC) have been associated with both sporadic interstitial lung disease (ILD) due to de novo mutations and familial ILD inherited as autosomal dominant (2-10). One particular SFTPC mutation, a substitution of threonine (T) for isoleucine (I) in codon 73 (I73T) has been identified in multiple unrelated families $(9-11)$. The age at onset and severity of lung disease due to SFTPC I73T as well as other SFTPC mutations is highly variable, ranging from death in early infancy to development of pulmonary fibrosis in the fifth or sixth decade $(7,9-12)$. SP-C deficiency in knock-

Received January 2, 2007; accepted March 23, 2007.

Correspondence: Lawrence M. Nogee, M.D., Division of Neonatology, CMSC 6-104, 600 N. Wolfe Street, Baltimore, MD 21287-3200; e-mail: lnogee@jhmi.edu

Supported by the National Institutes of Health (HL-54703 to L.M.N.) and the Eudowood Foundation. out mouse models results in lung disease depending on genetic background $(13,14)$. The variability in mouse and human lung disease suggests that SFTPC-associated lung disease may be influenced by environmental factors and/or modifier genes.

A candidate gene that may modify SFTPC-related lung disease is the ATP-binding cassette A3 ( $A B C A 3)$ gene. ABCA3 encodes a 1704-amino acid protein that is highly expressed in the lung and has been localized to the limiting membrane of lamellar bodies in alveolar type II cells (15-18). Recent studies support that ABCA3 transports lipids into lamellar bodies, the storage organelle for surfactant within alveolar type II cells and is required for the formation of normal lamellar bodies (19-21). Autosomal recessive ABCA3 deficiency results in fatal neonatal RDS (22), whereas some $A B C A 3$ mutations, also inherited in autosomal recessive fashion, are associated with ILD and prolonged survival (23). The lung histopathology in children with the milder phenotype is similar to that observed in children with SFTPC mutations. We hypothesized that $A B C A 3$ genetic variants modify the pulmonary phenotype of some SFTPC mutations.

\section{METHODS}

Patients. From June 1993 through December 2005, DNA samples were obtained from 325 children with chronic lung disease of unknown etiology as part of a study to identify genetic defects in surfactant metabolism. The entry criteria included the following: (1) gestational age of $36 \mathrm{wk}$ or older and age $30 \mathrm{~d}$ or older or discharged from the neonatal intensive care unit or gestational age younger than $36 \mathrm{wk}$ and age older than 3 mo or discharge from the neonatal intensive care unit and (2) indications of parenchymal lung disease as manifested by two of three of the following factors: need for supplemental oxygen; clinical signs of lung disease, including cough, tachypnea, retractions, or rales; and abnormal chest radiograph. Infants younger than $30 \mathrm{~d}$ were eligible for enrollment if there was a family history of lung disease. A history of neonatal lung disease was not a requirement for inclusion. The children were referred by their primary providers. The review boards of the participating institutions approved the protocols for these evaluations, and written consent for genetic testing was obtained from the families. Patients were not excluded based on sex or race/ethnicity. Fifty-six percent was male, $43 \%$ female, and $1 \%$ unknown. The distribution of samples by racial/ethnic background was 218 (67\%) white (non-Hispanic), 23 (7\%) African American, $41(12.5 \%)$ Hispanic, 15 (4.5\%) Asian, $6(1.8 \%)$ other, and $17(5.2 \%)$ unknown.

DNA preparation and mutational analysis. Genomic DNA was prepared from blood leukocytes with use of a commercially available kit (Gentra Systems, Minneapolis, MN). Polymerase chain reaction (PCR) products spanning exons 1 and 2 (genomic positions, -143 to 996) and exons 3 to 6

Abbreviations: $\boldsymbol{A B C A 3}$, adenosine triphosphate-binding cassette protein group A3 gene; pILD, pediatric interstitial lung disease; SFTPC, surfactant protein $\mathrm{C}$ gene 


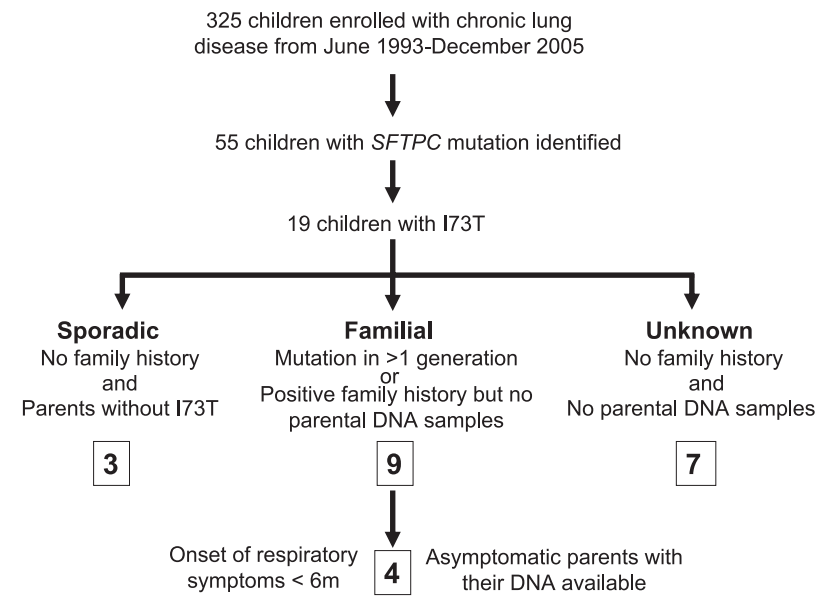

Figure 1. Flow table for selection of children with chronic lung disease and SFTPC I73T for ABCA3 gene analysis. Seven of these patients were the subject of earlier reports.

(genomic positions, 1212 to 2522) of the SFTPC gene were generated from genomic DNA by PCR and analyzed by direct sequencing of the PCR products with the use of previously described conditions (24). The 30 coding exons of the $A B C A 3$ gene and their respective splice junction sites were amplified by previously published conditions and primer sets (23). Automated DNA sequencing was performed through the Johns Hopkins School of Medicine's genetic resources core DNA sequencing facility using Applied Biosystems 3730 DNA Analyzer (Applied Biosystems). DNA sequencing chromatograms were analyzed with the aid of Sequencher 4.2 software (Gene Codes Corporation, Ann Arbor, MI). The resulting ABCA3 and SFTPC sequences were compared with reference sequences $(15,25)$.

Restriction digest analysis. The restriction endonuclease BsrGI was purchased from New England Biolabs (Beverly, MA) and used according to manufacturer's specifications for analysis of $A B C A 3 \mathrm{E} 292 \mathrm{~V}$, as reported previously (23).

\section{RESULTS}

Of the 325 children enrolled in the study, 55 (17\%) were found to have an SFTPC mutation identified as the probable cause of their lung disease. SFTPC I73T was the most commonly identified mutation, found in 19 children, which comprised 35\% of the mutant SFTPC alleles. Seven of the 19 children were the subject of an earlier report, including one who was a compound heterozygote for SFTPC I73T and SFTPC L110R (10). ABCA3 E292V was assayed for in the 19 children because of its association with multiple unrelated children and lung disease (23). Two infants were identified with $A B C A 3 \mathrm{E} 292 \mathrm{~V}$ and had the onset of their symptoms at younger than 2 mo of age. Each parent did not have any respiratory symptoms, and DNA samples were available from both parents for analysis (Fig. 1). Two additional infants were discordant in their respiratory symptoms from their parents
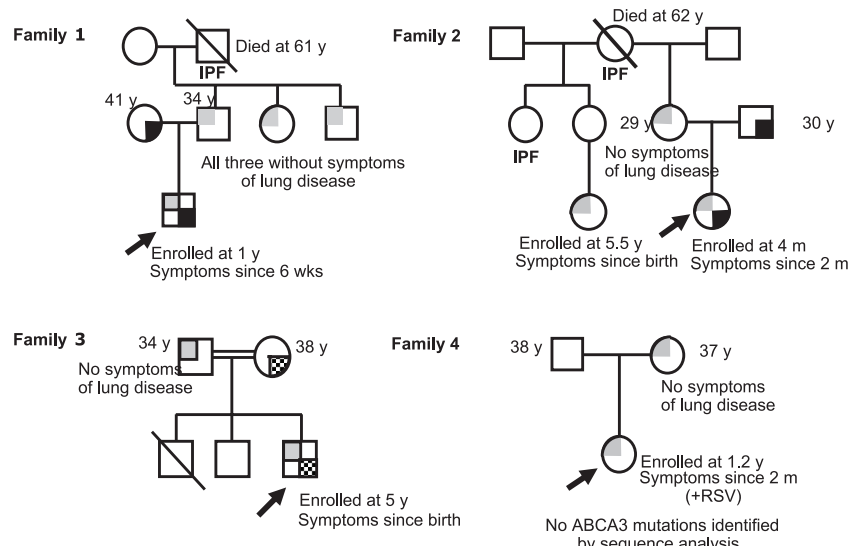

Figure 2. Pedigrees of patients with SFTPC I73T evaluated for $A B C A 3$ mutations. Index cases identified by arrows with age at enrollment and onset of symptoms noted below symbol. Age of parents and symptomatic family members are noted below symbol. Circle, female; square, male; shaded quarter symbol, SFTPC I73T; solid quarter symbol, ABCA3 E292V; checkered quarter symbol, ABCA3 L212M; slash through symbol, deceased; IPF, idiopathic pulmonary fibrosis; RSV, respiratory syncytial virus.

and also had available DNA from the both of their parents (Table 1). The 30 coding exons of $A B C A 3$ were sequenced from these four children. Sequencing confirmed that patients 1 and 2 had the $A B C A 3 \mathrm{E} 292 \mathrm{~V}$ mutation and no other mutation. Patient 3 was heterozygous for a missense mutation in exon 8 , a substitution of methionine for leucine at codon 212, L212M. Patient 4 did not have any mutations identified. Analysis of parental DNA of three children who were heterozygous for both SFTPC I73T, and an ABCA3 mutation demonstrated that the $A B C A 3$ mutation was inherited from the opposite parent who had SFTPC I73T (Fig. 2).

\section{DISCUSSION}

There are many examples of monogenic disorders whose phenotype is influenced by modifier genes, such as polymorphisms that affect the expression of fetal $\mathrm{Hb}$ in sickle cell disease (26). We chose $A B C A 3$ as a candidate modifier gene for the lung disease due to SFTPC mutations because of its involvement in surfactant metabolism and the similarities in the lung pathology findings in children with $A B C A 3$ mutations to those with $S F T P C$-related lung disease. To test this hypothesis, we selected families with the most severe pulmonary phenotypic discordance, each with an affected infant whose respiratory symptoms began at younger than 2 mo of age and an asymptomatic parent with SFTPC I73T. We focused on families with SFTPC I73T, as it is the most frequently re-

Table 1. Characteristics of infants with SFTPC I73T and asymptomatic parents

\begin{tabular}{lllll}
\hline & Patient 1 & Patient 2 & & Patient 3 \\
\hline Race & White & White & White, Middle Eastern descent & White \\
Age at symptoms & $6 \mathrm{wk}$ & Birth $(\mathrm{TTN})$ & Birth & Birth (TTN) \\
Sex & Male & Female & Male & Female \\
Age at enrollment & $13 \mathrm{mo}$ & $4 \mathrm{mo}$ & $5 \mathrm{yo}$ mo & Not done \\
Lung biopsy & Not done & Not done & Cholesterol pneumonitis with mild fibrosis & $25 \mathrm{mo}$ \\
Current age & $30 \mathrm{mo}$ & $22 \mathrm{mo}$ & $7 \mathrm{y}$ & None \\
Family history & Yes & Yes & Yes & \\
\hline
\end{tabular}

TTN, transient tachypnea of newborns. 
ported SFTPC mutation associated with lung disease, (9-12) and to minimize effects on disease severity due to different SFTPC mutations. Three of four infants were also heterozygous for an $A B C A 3$ mutation, supporting a role for $A B C A 3$ in modifying lung disease due to $S F T P C$ mutations.

Two of the four infants had $A B C A 3 \mathrm{E} 292 \mathrm{~V}$, a mutation that has been associated with pILD (23). The population frequency of $A B C A 3 \mathrm{E} 292 \mathrm{~V}$ is low, approximately one in 275 individuals (personal communication, T. Garmany and A. Hamvas). Thus, the finding of $A B C A 3 \mathrm{E} 292 \mathrm{~V}$ in two of the 19 patients with SFTPC I73T seems unlikely to have occurred by chance. The third infant had a different missense mutation, $A B C A 3$ L212M, which results in a conservative neutral substitution. It is possible that $\mathrm{L} 212 \mathrm{M}$ represents a rare but benign polymorphism. However, two siblings with significant respiratory symptoms and who had lung histopathology findings consistent with surfactant dysfunction were compound heterozygotes for a previously identified $A B C A 3$ nonsense mutation (R106X) and L212M, suggesting that L212M is a diseasecausing mutation (L.M. Nogee, unpublished data). No $A B C A 3$ mutation was identified in the fourth infant. Other genetic modifiers or other critical environmental exposures may have contributed to the severity of lung disease, in particular a respiratory syncytial virus infection at 2 mo of age. A history of viral infections was noted in symptomatic young infants in a large kindred with familial ILD due to SFTPC L188Q (7). In addition, RSV infection of cells in culture that expressed a low level of a SFTPC mutation identified in patients with ILD that skips exon 4 (SFTPC $\triangle$ exon4) resulted in cell death, indicating a possible interaction of low levels of expression of abnormal SP-C with viral infections (27).

The pathophysiology of $S F T P C$-related lung disease is complex, and the mechanisms whereby $A B C A 3$ mutations modify the lung disease due to SFTPC mutations are unknown. SFTPC mutations may cause SP-C deficiency by a dominant negative mechanism. Mature SP-C is derived from a larger proprotein (proSP-C) that self-associates in the secretory pathway (28). ProSP-C containing mutations may be targeted for degradation (29). Thus, abnormal SP-C may also cause wild-type SP-C to be degraded, leading to SP-C deficiency. Decreased or absent SP-C has been observed in some patients with SFTPC mutations $(3,24,30)$. As ABCA3 deficiency alters surfactant homeostasis, including abnormal processing and routing of SP-C (31) and hindering lamellar body biogenesis (19), decreased functional ABCA3 activity in patients with SFTPC mutations may result in more severe symptoms of surfactant deficiency. We did not perform expression studies to directly assess the effects of the $A B C A 3$ mutations observed in these patients.

Lung disease due to SFTPC mutations may result from a toxic gain-of-function mechanism of abnormal proSP-C. Increased proSP-C expression may overwhelm the protein degradation pathway leading to abnormal accumulations of proSP-C containing mutations. Perinuclear accumulations of mutated proSP-C have been observed in vitro $(32,33)$ and in explanted lung tissue from a patient with an SFTPC mutation (6). These accumulations of abnormal protein may result in the unfolded protein response, cytotoxicity, and eventual ap- optotic death $(5,34)$. Expression of SFTPC $\triangle$ exon4 in transgenic mice disrupted lung development that correlated with the degree of transgene expression, further supporting the potential toxicity of abnormal proSP-C (29). Altered surfactant homeostasis with abnormal processing and routing of SP-C due to decreased ABCA3 function (31) may thus exacerbate the accumulation of inappropriately processed SP-C, leading to more cell injury and death. Both loss-of-function and toxic gain-of-function mechanisms may be involved in the development of $S F T P C$-related lung disease at different points in time.

The relative contribution of $A B C A 3$ to $S F T P C$-related lung disease is unknown. Our study was not population based with enrolled infants identified by their primary physicians based on the unusual nature of their lung disease, and we selected those infants for whom we had parental DNA and whom knew had variable severity of lung disease. There is thus a significant ascertainment bias that limits interpretation of the frequency of $A B C A 3$ as a gene that modifies some SFTPC mutations.

In summary, the finding that three infants with severe lung disease and SFTPC I73T were also heterozygous for $A B C A 3$ mutations, in contrast to their asymptomatic parents from whom they inherited the SFTPC mutation, supports the hypothesis that $A B C A 3$ mutations modify the severity of lung disease associated with SFTPC mutations. Studies of the effects of SFTPC mutations in combination with $A B C A 3$ mutations both in vitro and ultimately in animal models will be needed to confirm this hypothesis. We speculate that $A B C A 3$ genetic variants may also contribute to the development and progression of other common diseases in the general population, such as asthma or bronchopulmonary dysplasia.

\section{REFERENCES}

1. Weaver TE, Conkright JJ 2001 Function of surfactant proteins B and C. Annu Rev Physiol 63:555-578

2. Tredano M, Griese M, Brasch F, Schumacher S, de Blic J, Marque S, Houdayer C, Elion J, Couderc R, Bahuau M 2004 Mutation of SFTPC in infantile pulmonary alveolar proteinosis with or without fibrosing lung disease. Am J Med Genet A 126:18-26

3. Nogee LM, Dunbar AE 3rd, Wert SE, Askin F, Hamvas A, Whitsett JA 2001 A mutation in the surfactant protein $\mathrm{C}$ gene associated with familial interstitial lung disease. N Engl J Med 344:573-579

4. Amin RS, Wert SE, Baughman RP, Tomashefski JF Jr, Nogee LM, Brody AS, Hull WM, Whitsett JA 2001 Surfactant protein deficiency in familial interstitial lung disease. J Pediatr 139:85-92

5. Beers MF, Mulugeta S 2005 Surfactant protein C biosynthesis and its emerging role in conformational lung disease. Annu Rev Physiol 67:663-696

6. Hamvas A, Nogee LM, White FV, Schuler P, Hackett BP, Huddleston CB, Mendeloff EN, Hsu FF, Wert SE, Gonzales LW, Beers MF, Ballard PL 2004 Progressive lung disease and surfactant dysfunction with a deletion in surfactant protein C gene. Am J Respir Cell Mol Biol 30:771-776

7. Thomas AQ, Lane K, Phillips J 3rd, Prince M, Markin C, Speer M, Schwartz DA, Gaddipati R, Marney A, Johnson J, Roberts R, Haines J, Stahlman M, Loyd JE 2002 Heterozygosity for a surfactant protein $\mathrm{C}$ gene mutation associated with usual interstitial pneumonitis and cellular nonspecific interstitial pneumonitis in one kindred. Am J Respir Crit Care Med 165:1322-1328

8. Stevens PA, Pettenazzo A, Brasch F, Mulugeta S, Baritussio A, Ochs M, Morrison L, Russo SJ, Beers MF 2005 Nonspecific interstitial pneumonia, alveolar proteinosis, and abnormal proprotein trafficking resulting from a spontaneous mutation in the surfactant protein C gene. Pediatr Res 57:89-98

9. Lawson WE, Grant SW, Ambrosini V, Womble KE, Dawson EP, Lane KB, Markin C, Renzoni E, Lympany P, Thomas AQ, Roldan J, Scott TA, Blackwell TS, Phillips JA 3rd, Loyd JE, du Bois RM 2004 Genetic mutations in surfactant protein C are a rare cause of sporadic cases of IPF. Thorax 59:977-980

10. Cameron HS, Somaschini M, Carrera P, Hamvas A, Whitsett JA, Wert SE, Deutsch G, Nogee LM 2005 A common mutation in the surfactant protein $\mathrm{C}$ gene associated with lung disease. J Pediatr 146:370-375 
11. Brasch F, Griese M, Tredano M, Johnen G, Ochs M, Rieger C, Mulugeta S, Muller KM, Bahuau M, Beers MF 2004 Interstitial lung disease in a baby with a de novo mutation in the SFTPC gene. Eur Respir J 24:30-39

12. Percopo S, Cameron HS, Nogee LM, Pettinato G, Montella S, Santamaria F 2004 Variable phenotype associated with SP-C gene mutations: fatal case with the I73T mutation. Eur Respir J 24:1072-1073

13. Glasser SW, Burhans MS, Korfhagen TR, Na CL, Sly PD, Ross GF, Ikegami M, Whitsett JA 2001 Altered stability of pulmonary surfactant in SP-C-deficient mice. Proc Natl Acad Sci U S A 98:6366-6371

14. Glasser SW, Detmer EA, Ikegami M, Na CL, Stahlman MT, Whitsett JA 2003 Pneumonitis and emphysema in sp-C gene targeted mice. J Biol Chem 278:1429114298

15. Connors TD, Van Raay TJ, Petry LR, Klinger KW, Landes GM, Burn TC 1997 The cloning of a human $\mathrm{ABC}$ gene $(\mathrm{ABC} 3)$ mapping to chromosome 16p13.3. Genomics 39:231-234

16. Yamano G, Funahashi H, Kawanami O, Zhao LX, Ban N, Uchida Y, Morohoshi T, Ogawa J, Shioda S, Inagaki N 2001 ABCA3 is a lamellar body membrane protein in human lung alveolar type II cells. FEBS Lett 508:221-225

17. Mulugeta S, Gray JM, Notarfrancesco KL, Gonzales LW, Koval M, Feinstein SI, Ballard PL, Fisher AB, Shuman H 2002 Identification of LBM180, a lamellar body limiting membrane protein of alveolar type II cells, as the ABC transporter protein ABCA3. J Biol Chem 277:22147-22155

18. Zen K, Notarfrancesco K, Oorschot V, Slot JW, Fisher AB, Shuman H 1998 Generation and characterization of monoclonal antibodies to alveolar type II cell lamellar body membrane. Am J Physiol 275:L172-L183

19. Cheong N, Madesh M, Gonzales LW, Zhao M, Yu K, Ballard PL, Shuman H 2006 Functional and trafficking defects in ATP binding cassette A3 mutants associated with respiratory distress syndrome. J Biol Chem 281:9791-9800

20. Nagata K, Yamamoto A, Ban N, Tanaka AR, Matsuo M, Kioka N, Inagaki N, Ueda K 2004 Human ABCA3, a product of a responsible gene for abca3 for fatal surfactant deficiency in newborns, exhibits unique ATP hydrolysis activity and generates intracellular multilamellar vesicles. Biochem Biophys Res Commun 324:262-268

21. Garmany TH, Moxley MA, White FV, Dean M, Hull WM, Whitsett JA, Nogee LM, Hamvas A 2006 Surfactant composition and function in patients with ABCA3 mutations. Pediatr Res 59:801-805

22. Shulenin S, Nogee LM, Annilo T, Wert SE, Whitsett JA, Dean M 2004 ABCA3 gene mutations in newborns with fatal surfactant deficiency. N Engl J Med 350:12961303
23. Bullard JE, Wert SE, Whitsett JA, Dean M, Nogee LM 2005 ABCA3 mutations associated with pediatric interstitial lung disease. Am J Respir Crit Care Med 172:1026-1031

24. Nogee LM, Dunbar AE 3rd, Wert S, Askin F, Hamvas A, Whitsett JA 2002 Mutations in the surfactant protein $\mathrm{C}$ gene associated with interstitial lung disease. Chest 121:20S-21S

25. Warr RG, Hawgood S, Buckley DI, Crisp TM, Schilling J, Benson BJ, Ballard PL, Clements JA, White RT 1987 Low molecular weight human pulmonary surfactant protein (SP5): isolation, characterization, and cDNA and amino acid sequences. Proc Natl Acad Sci U S A 84:7915-7919

26. Chui DH, Dover GJ 2001 Sickle cell disease: no longer a single gene disorder. Curr Opin Pediatr 13:22-27

27. Bridges JP, Xu Y, Na CL, Wong HR, Weaver TE 2006 Adaptation and increased susceptibility to infection associated with constitutive expression of misfolded SP-C J Cell Biol 172:395-407

28. Conkright JJ, Bridges JP, Na CL, Voorhout WF, Trapnell B, Glasser SW, Weaver TE 2001 Secretion of surfactant protein $C$, an integral membrane protein, requires the N-terminal propeptide. J Biol Chem 276:14658-14664

29. Bridges JP, Wert SE, Nogee LM, Weaver TE 2003 Expression of a human surfactan protein $\mathrm{C}$ mutation associated with interstitial lung disease disrupts lung development in transgenic mice. J Biol Chem 278:52739-52746

30. Nogee LM 2002 Abnormal expression of surfactant protein $\mathrm{C}$ and lung disease. Am J Respir Cell Mol Biol 26:641-644

31. Brasch F, Schimanski S, Muhlfeld C, Barlage S, Langmann T, Aslanidis C, Boettcher A, Dada A, Schroten H, Mildenberger E, Prueter E, Ballmann M, Ochs M, Johnen G, Griese M, Schmitz G 2006 Alteration of the pulmonary surfactant system in full-term infants with hereditary ABCA3 deficiency. Am J Respir Crit Care Med 174:571-580

32. Beers MF, Lomax CA, Russo SJ 1998 Synthetic processing of surfactant protein C by alveolar epithelial cells. The $\mathrm{COOH}$ terminus of proSP-C is required for post-translational targeting and proteolysis. J Biol Chem 273:15287-15293

33. Kabore AF, Wang WJ, Russo SJ, Beers MF 2001 Biosynthesis of surfactant protein $\mathrm{C}$ : characterization of aggresome formation by EGFP chimeras containing propeptide mutants lacking conserved cysteine residues. J Cell Sci 114:293-302

34. Mulugeta S, Nguyen V, Russo SJ, Muniswamy M, Beers MF 2005 A surfactant protein $\mathrm{C}$ precursor protein BRICHOS domain mutation causes endoplasmic reticulum stress, proteasome dysfunction, and caspase 3 activation. Am J Respir Cell Mol Biol 32:521-530 